\title{
Studying the thermo-oxidative stability of chars using pyrolysis-combustion flow calorimetry
}

\author{
Rodolphe Sonnier $^{\mathrm{a},{ }^{*}, \text { Amandine Viretto }}{ }^{\mathrm{a}}$, Belkacem Otazaghine ${ }^{\mathrm{a}}$, Loïc Dumazert ${ }^{\mathrm{a}}$, Alexei Evstratov ${ }^{\mathrm{a}}$, \\ Jean-Claude Roux ${ }^{\mathrm{a}}$, Cai Heruijing ${ }^{\mathrm{a}}$, Charlene Presti ${ }^{\mathrm{b}}$, \\ Johan G. Alauzun ${ }^{\text {b }}$, P. Hubert Mutin ${ }^{\text {b }}$, Henri Vahabi ${ }^{\text {c }}$ \\ a Centre des Matériaux des Mines d'Ales (C2MA), 6, Avenue de Clavieres, 30319, Ales Cedex, France \\ b Institut Charles Gerhardt Montpellier, UMR 5253, CNRS-UM-ENSCM, Université de Montpellier, Place Eugene Bataillon, CC1701, F-34095, Montpellier Cedex 5, France \\ ${ }^{\mathrm{c}}$ Université de de Lorraine, Laboratoire MOPS, E.A. 4423, Metz F, 57070, France
}

\section{A B S T R A C T}

A method to estimate the thermo oxidative stability of chars is proposed using pyrolysis combustion flow calorimetry. The temperature of char degradation is measured for different oxygen fractions (from 0.01 to 0.4 , i.e. from 0 to $40 \%$ ) into the pyrolyzer. Then the thermo oxidative stability versus the oxygen fraction is modelled using a simple phenomenological equation. Two parameters have been calculated: the first one predicts the temperature of char degradation in "pure" oxygen and the second one corresponds to the sensitivity of the char degradation temperature to the oxygen fraction. These two parameters allow comparing the chars obtained from different materials after various pyrolysis pro cedures. Rough relationships between these two parameters and the elemental composition of char are identified. Phosphorus allows improving the thermo oxidative stability of chars as expected but its effect is nonlinear. Lignocellulosic materials lead to chars with low thermal stability even when the phosphorus content is high. Finally, the obtained results show that the char elemental composition is not the only parameter influencing its thermo oxidative stability.

\section{Introduction}

During burning, many polymeric materials form a carbonaceous or partly carbonaceous residue. This residue can act as a protective insulating layer. Except in the case of porous materials [1], pyrolysis is believed to be anaerobic as long as the flame is sustained. But when the flame vanishes, the residue can undergo aerobic pyrolysis (or thermo oxidation) at the end of cone calorimeter test for example. Chars from textiles also undergo thermo oxidation when a small flame propagates, as evidenced in a previous article [2]. A critical situation is probably the use of intumescent coating to protect structural materials. The expanded carbonaceous layer must protect the underlying material for several hours. The char layer must fulfil some requirements to be efficient. Cohesion, thickness, porosity are important properties influencing the barrier effect of this char layer. Above all, the thermal stability of the char is a critical parameter.

\footnotetext{
* Corresponding author.

E-mail address: rodolphe.sonnier@mines-ales.fr (R. Sonnier).
}

Aerobic pyrolysis (thermo oxidation) of carbonaceous materials is a heterogeneous catalysis which has been extensively studied, in particular by scientists working on the coal boiler efficiency [3]. Indeed, the rate of $\mathrm{C}-\mathrm{O}_{2}$ reaction has a strong effect on efficiency of combustion, heat transfer and particulate removal processes. The intrinsic reactivity of carbon to oxygen depends on the temperature and activation energies were found in the range $126-290 \mathrm{~kJ} / \mathrm{mol}$ [4]. But the reactivity of true coals and chars may deviate from the intrinsic reactivity due to a couple of parameters. Many studies have been carried out for several decades on coals or chars pre pared from coals.

One main result from these studies is that the reactivity of carbon to oxygen decreases when carbon ordering increases. Several methods were developed to characterize the carbonaceous structure of coals and chars. $\mathrm{X}$ ray diffraction is an appropriate method to assess the structural changes of a carbonaceous material during heat treatment, including fraction of amorphous carbon, aromaticity and crystallite size $[5,6]$. Other methods include Raman spectroscopy $[7,8]$, nuclear magnetic resonance or high resolution transmission electron microscopy [9]. The $\mathrm{H} / \mathrm{C}$ ratio is indicative 
of aromatization and the reactivity was found to decrease when the ratio decreases [10]. Reactivity of oxygen was found to be well correlated with a disorder index taking into account amorphous fraction and aromaticity [11].

Other fuel properties have obviously a strong influence on reactivity of carbon to oxygen. Size and porosity of particles influ ence the diffusion of oxygen [12]. The presence of catalytic ele ments (magnesium, calcium...) has been pointed out as one of the most influent parameters on reactivity to oxygen [13].

The ordering of carbonaceous material as well as the morphology of coal/char particles influences its reactivity to oxy gen but is also evolutive upon heat treatment. Since the combus tion conditions (temperature, heating rate, residence time) change from one boiler to another one, the effect of these conditions on the reactivity has been studied $[10,14,15]$. Temperature reached during char preparation and heating rate are two parameters influencing the organization of char. Davis et al. explain that the typical com bustion conditions are insufficient to lead to true graphitization but allow the growth of regions of turbostratic order [16]. As an example, char deactivation was observed by Russell et al. [9] after treatment at high temperature. The presence of $1 \%$ of oxygen dur ing steam gasification of brown coal leads to a lower reactivity of char because oxygen enhances the generation of $\mathrm{H}$ radicals which promote the condensation of aromatic ring systems and a more ordered structure [8].

There is a real need to understand the influence of the compo sition and the structure of chars on their thermo oxidative stability. Nevertheless, the relations between carbonaceous structure and reactivity to oxygen are out of the scope of this article. The main goal of this work is to propose a convenient method to study the reactivity of chars to oxygen using a henceforth well known apparatus available in many fire laboratories. The thermo oxidative stability is studied using a pyrolysis combustion flow calorimeter (PCFC) upon a wide range of oxygen fraction in pyrol ysis chamber (0-0.4, i.e. from 0 to $40 \%$ ). The PCFC analysis is most generally used in standard conditions [17] (i.e. anaerobic pyrolysis followed by a complete combustion of gases). Nevertheless, other conditions (incomplete combustion, aerobic pyrolysis) can be applied to obtain new insights on materials properties.

This new method may allow identifying the influence of various charring promoters on the thermo oxidative stability of the char. Among charring promoters, phosphorus based compounds are nowadays an important class of flame retardants (FRs) [18,19]. Other flame retardants, as some metal hydroxides [20], can also promote charring of polymers. Some materials are intrinsically charring as polycarbonate, for example. It is also the case of ligno cellulosic fibers which are considered to be promising alternatives to replace glass fibers due to their excellent mechanical properties [21]. In the present article, we have studied the thermo oxidative stability of chars obtained from the degradation of various mate rials: charring polymers, flax fibers grafted with phosphonate based molecules, epoxy resins flame retarded with phosphorus containing additives, polybutylene terephthalate containing aluminum based flame retardants and phosphorus containing nanodiamonds. The denomination of char is used in this article for various residues obtained from organic materials after a first degradation step whichever the heating conditions. The residues can be partly carbonaceous and partly inorganic.

\section{Experimental}

\subsection{Materials}

Poly(ether ether ketone) (PEEK 151G Natural) was provided by Victrex. Polycarbonate (PC Makrolon 2647) was provided by Bayer
SA. Poly(butylene terephthalate) (PBT Vestodur 3000) was pro vided by from Evonik.

Dried flax fibers used in this study were extracted from a fabric kindly provided by Hexcel. The fibers had the following composi tion: cellulose ( $81 \mathrm{wt} \%$ ), hemicellulose (13 wt\%), lignin (2.7 wt\%). This composition was in a good agreement with literature data [22-24]. Dimethylvinyl phosphonate (MVP) from Acetolac was grafted onto flax fibers. While MVP was grafted in the bulk, its content can reach high level (up to $17 \mathrm{wt} \%$ ). The grafting method (e beam irradiation) and the characterization of the modified flax fi bers have been described elsewhere [2].

Epoxy resin was flame retarded with phloroglucinoltris(diethyl phosphate) ( $\mathrm{P} 3 \mathrm{P}(\mathrm{OEt}))$. Flame retardant was prepared as described by Menard et al. [25]. Ammonium polyphosphate (APP

Exolit APP423 provided by Clariant) was also incorporated into epoxy resin according to the same procedure. APP content was fixed to $9.4 \mathrm{wt} \%$ in order to maintain a phosphorus content equal to $3 \mathrm{wt} \%$.

Polyamides were flame retarded with two organophosphorus silica generated in situ from alkoxysilanes called SiP and SiDOPO. The preparation methods of SiP and SiDOPO as well as the char acterization of the composites can be found elsewhere [26,27].

Magnesium hydroxide (MDH Magnifin H10) was provided by Albermarle. Particles median size was $0.8 \mu \mathrm{m}$. Its efficiency as char promoter in polyesters, and particularly PBT, has been extensively studied in Viretto et al. [20].

Poly(butylene terephthalate) (PBT) composites were prepared by incorporating $10 \mathrm{wt} \%$ of pure $\gamma$ alumina and modified $\gamma$ alumina. The alumina from Prolabo was crushed by grinder (Retsch S1000) into $160-315 \mu \mathrm{m}$ particles. Nickel sulfate was dissolved in water and dripped slowly on the alumina surface. The mixture obtained was dried at $150{ }^{\circ} \mathrm{C}$ for $24 \mathrm{~h}$, and then oxidized at $550{ }^{\circ} \mathrm{C}$ for $6 \mathrm{~h}$, followed by the $\mathrm{H}_{2} / \mathrm{N}_{2}$ flow reduction for $3 \mathrm{~h}$ in order to form metallic nickel $\left(\mathrm{Ni}^{0}\right)$ on alumina. The $\mathrm{H}_{2}$ and $\mathrm{N}_{2}$ flows were $75 \mathrm{ml} / \mathrm{min}$ and $150 \mathrm{ml} / \mathrm{min}$ respectively, the reduction temperature was $750{ }^{\circ} \mathrm{C}$. The procedure has already been described by Majoli et al. [28]. PBT was compounded with additives in the micro compounder (DSM). Processing was operated at $247^{\circ} \mathrm{C}$ at $80 \mathrm{rpm}$ during $10 \mathrm{~min}$. The composites were prepared under nitrogen at mosphere to avoid the degradation of PBT.

Nanodiamonds (International Technology Center, Raleigh, NC, U.S.A.) were also studied as model materials. Such materials were modified through surface phosphorylation [29]. Phosphorylation leads to a strong improvement of the thermo oxidative stability measured using dynamic and isothermal thermogravimetric ana lyses in air, as already reported by Presti et al. [29]. Details about all these materials are given in Table 1.

\subsection{Methods}

The flammability was studied using a Pyrolysis Combustion Flow Calorimeter (PCFC) from Fire Testing Technology (FTT). Heating rate, maximum pyrolysis temperature, combustion tem perature and gas flow rate were respectively $1^{\circ} \mathrm{C} \mathrm{s}^{-1}, 750^{\circ} \mathrm{C}, 900^{\circ} \mathrm{C}$ (corresponding to complete combustion) and $100 \mathrm{~cm}^{3} \mathrm{~min}^{-1}$. Ox ygen was introduced at various fractions (up to 0.4 ) into the py rolyzer to measure the thermo oxidative stability of the char. When the method is applied, the oxygen fractions in pyrolyzer and in combustor are not independent. Therefore, if low oxygen fractions are chosen for aerobic pyrolysis, oxygen may be fully consumed and the combustion may become incomplete. To avoid this issue, the weights of samples were carefully chosen for each test. For example, in most cases (low to medium peak of heat release rate), a $1 \mathrm{mg}$ sample can be successfully tested even with a very low oxy gen fraction (0.01) in pyrolyzer. 
In order to highlight the influence of preparation method of chars as already pointed out in literature [10], some chars were obtained from cone calorimeter (Fire Testing Technology, FTT) tests according to ISO5660 standard. Heat flux was fixed at $50 \mathrm{~kW} / \mathrm{m}^{2}$. Chars were removed arbitrarily two minutes after flaming out.

The solid residues were observed using a FEI Quanta 200 scanning electron microscope and their elemental compositions (C, $\mathrm{O}, \mathrm{P}, \mathrm{Si}$ atoms) were determined by Energy Dispersive $\mathrm{X}$ ray spec troscopy (EDX) using Oxford INCA Energy 300 system and a de tector of $133 \mathrm{eV}$ (at $\mathrm{Mn}$ ). Note that the hydrogen fraction cannot be measured using this method. The P content in phosphorylated nanodiamonds was determined by ICP OES [21].

\subsection{Description of the test method}

In the following, "char" is referred to the carbonaceous part of residue undergoing the degradation during aerobic pyrolysis. Keep in mind that in many cases the residue is not only constituted by a carbonaceous part but also by an inorganic part.

Nanodiamonds were studied according to a specific procedure as discussed below. All other materials were subjected to a first pyrolysis step in anaerobic atmosphere up to $500-600{ }^{\circ} \mathrm{C}$ (when the heat release rate is stable and equal to 0 ) in PCFC. The obtained residues were cooled down to room temperature and a second degradation step was carried out under aerobic atmosphere up to $800{ }^{\circ} \mathrm{C}$ in order to degrade the char, still using PCFC. This procedure is considered as the standard one.

In all cases, the temperature of peak of Heat Release Rate (pHRR) (called $T_{f_{O_{2}}}$, i.e. char degradation temperature when oxygen fraction $f_{\mathrm{O}_{2}}$ ) decreases when the oxygen fraction increases. The pHRR temperature changes according to Equation (1):

$T_{f_{\mathrm{O}_{2}}}(K) \quad T_{1}(K) \times f_{\mathrm{O}_{2}}^{-\alpha}$

Equation (1) can be easily linearized leading to Equation (2).

$\operatorname{Ln}\left(T_{f_{O_{2}}}\right) \quad \operatorname{Ln}\left(T_{1}\right) \quad \alpha \times \operatorname{Ln}\left(f_{O_{2}}\right)$,

where $f_{\mathrm{O}_{2}}$ is the oxygen fraction in pyrolysis chamber, $\mathrm{T}_{1}$ is the temperature of pHRR corresponding to the char degradation in pure oxygen atmosphere $\left(f_{\mathrm{O}_{2}} 1\right)$, and $\alpha$ is a parameter $(>0)$ corre sponding to the sensitivity of char degradation temperature to the oxygen fraction (the higher $\alpha$ is, the higher the sensitivity of char degradation temperature to the oxygen fraction is).

Figs. 1 and 2 show the change of the pHRR temperature versus the oxygen fraction in the case of a char prepared from poly carbonate (PC) anaerobic pyrolysis. The analyses were carried out for six oxygen fractions: $0.01,0.02,0.05,0.1,0.2,0.4$. Fig. 2 repre sents $\operatorname{Ln}\left(T_{f_{\mathrm{O}_{2}}}\right)$ versus $\operatorname{Ln}\left(f_{\mathrm{O}_{2}}\right)$ and shows that the experimental points are well fitted with equation (2) $\left(R^{2} \quad\right.$ 0.9981). For some materials, the temperature of pHRR at low oxygen fraction $(<0.02)$ is too high and only four or five oxygen fractions were used.

Equation (1) means that the temperature of char degradation increases when the oxygen fraction decreases and this change is faster and faster when the oxygen fraction becomes very low. On the contrary, when the oxygen fraction is high, the temperature of char degradation is almost constant.

The thermo oxidative stability of nanodiamonds has been studied directly. The temperature of pHRR is not observed due to a very good stability of these materials (see Fig. 3). In this case, Equation (1) was used considering the temperature when Heat Release Rate (HRR) reaches $50 \mathrm{~W} / \mathrm{g}$ (i.e. when the degradation starts). Of course, the parameters $\mathrm{T}_{1}$ and $\alpha$ determined by means of this modified method cannot be compared to those measured using the previous one.

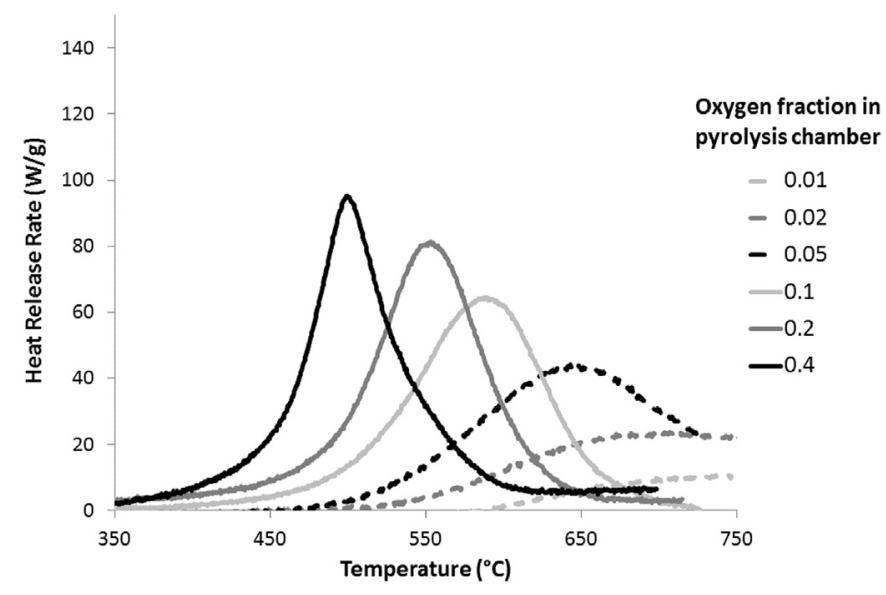

Fig. 1. Heat release rate curves for char prepared from polycarbonate (PC) anaerobic pyrolysis and degraded using various oxygen fractions.

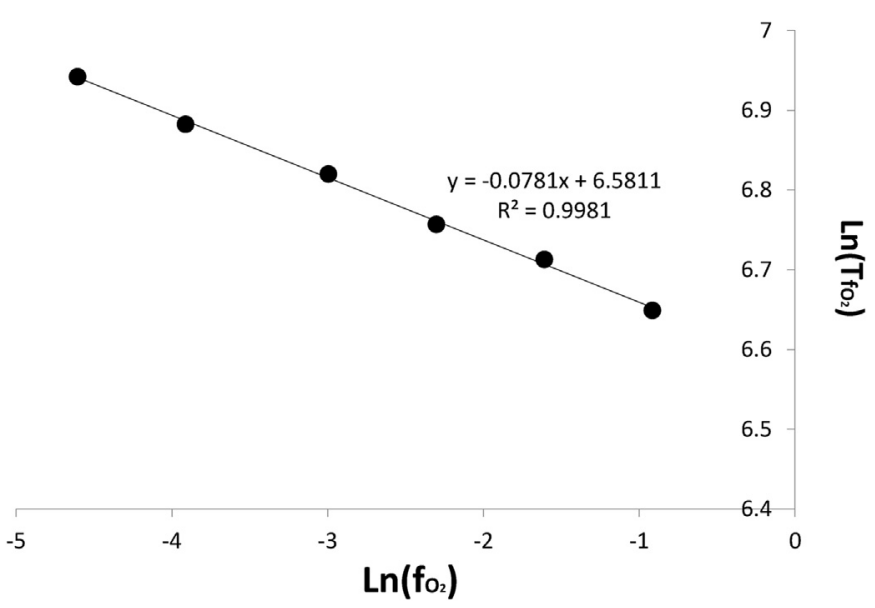

Fig. 2. $\operatorname{Ln}\left(T_{f_{0_{2}}}\right)$ versus $\operatorname{Ln}\left(f_{\mathrm{O}_{2}}\right)$ for char prepared from polycarbonate (PC) anaerobic pyrolysis.

A series of chars was prepared according to other procedures in order to assess the influence of particular conditions of char preparation. Two of these chars were sampled from the cone calorimeter tests and their properties were compared to those of

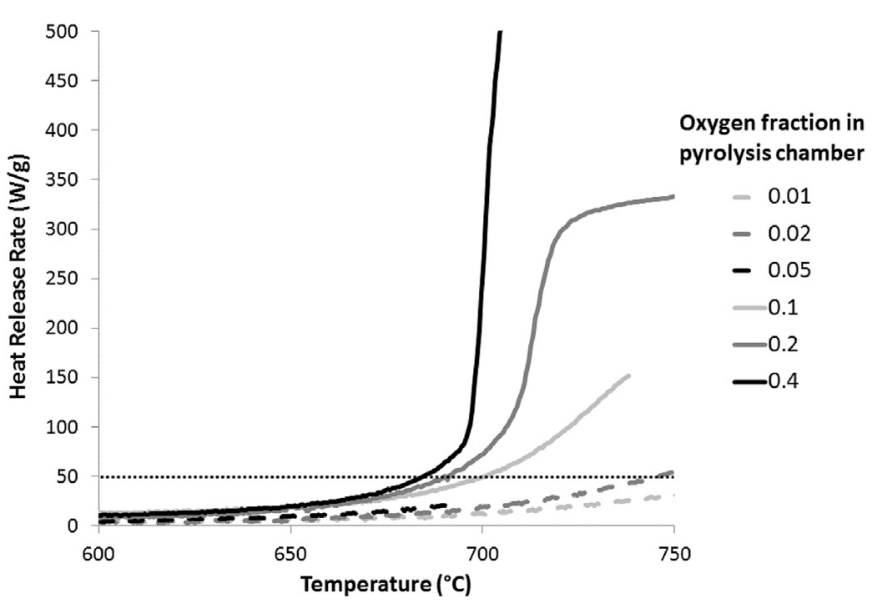

Fig. 3. Heat Release Rate (HRR) curves for ND5.15 using different oxygen fractions. 
the chars prepared according to the standard procedure from the same materials. Some flax fibers were also subjected directly to an aerobic degradation step. In this case, the heat release rate curve exhibits two steps. The first one corresponds to the degradation of flax fibers (especially cellulose component). The second one is assigned to the degradation of the char resulting from the first degradation step. Hence, in this case, the char is formed under aerobic conditions. The stability of the char was obviously evalu ated from the temperature of the second peak (see Fig. 4).

The method proposed here also allows studying the influence of oxygen fraction on heat release rate. Although such a study is out of the scope of the present article, an example about polycarbonate is given in supporting information 1. A brief comparison between PCFC results and thermogravimetric analyses is shown in supporting information 2.

\section{Results and discussion}

\subsection{Preliminary comments}

According to several authors, the decomposition rate $\dot{\omega}$ of a material in aerobic pyrolysis can be written as Equation (3) [30-32].

$\dot{\omega} \quad A e^{\frac{E}{R T}} f(\alpha) f_{O_{2}}^{\delta}$

where $f_{\mathrm{O}_{2}}$ is the oxygen fraction, $\mathrm{A}$ is the pre exponential factor, $\mathrm{E}$ is the energy of activation, $T$ the temperature, $R$ the universal con stant of gases, $\delta$ the reaction order for oxygen and $f(\alpha)$ the differ ential conversion function.

Note that this equation is only proposed to predict the kinetics of a complex process involving several heterogeneous solid state reactions but does not represent a "real" reaction. The set of ki netic parameters properly fitting the data is not unique and these parameters must be considered only as "numerical parameters" [30].

A very common result evidenced by this equation is that the decomposition rate increases when the oxygen fraction increases, which is obviously observed in the present work. Nevertheless, most of thermogravimetric analyses are carried out in nitrogen or in air and the data about the influence of oxygen on decomposition are scarce. $\mathrm{Hu}$ and You have studied the effect of oxygen into the pyrolysis of polyurethane. The oxygen fraction ranges from 0 to 0.5 . Even if the oxygen fraction affects the two decomposition steps at different extents, the authors show that oxygen promotes a faster

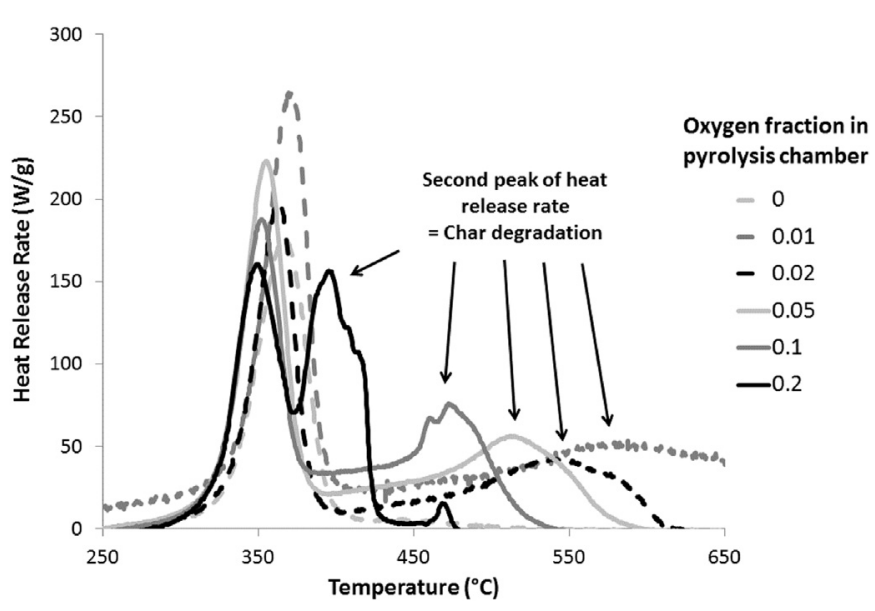

Fig. 4. HRR curves for flax fibers during direct aerobic pyrolysis. decomposition rate occurring at lower temperature [33]. This is in agreement with Equation (1) indicating that the temperature of char decomposition decreases with higher oxygen fraction.

\subsection{General results}

Fig. 5 and Table 2 summarize the main results obtained for all chars prepared according to the standard procedure. It can be observed that the temperature $\mathrm{T}_{1}$ ranges from 550 to $900 \mathrm{~K}$ (i.e. $277-627{ }^{\circ} \mathrm{C}$ ) and $\alpha$ ranges from 0.02 to 0.14 . As a rule, $\alpha$ decreases when $\mathrm{T}_{1}$ increases. In other words, a low char stability in pure ox ygen (low $\mathrm{T}_{1}$ ) is correlated with a high sensitivity of the char degradation temperature to the oxygen fraction (high $\alpha$, i.e. strong increase in thermo oxidative stability when the oxygen fraction decreases).

Untreated flax fibers were tested in duplicate. It appears that both series of measurements are consistent: $T_{1}$ is almost the same (554-560 K) and $\alpha$ is in the range $0.087-0.097$, which is relatively narrow in comparison to the range obtained for all materials tested $(0.021-0.135)$.

Fig. 6 compares the chars exhibiting the worst and the best thermo oxidative stabilities: these two chars are respectively un treated flax fibers (standard procedure) and epoxy containing ammonium polyphosphate (sampled from the cone calorimeter test). The difference in the thermo oxidative stability is very important: $242{ }^{\circ} \mathrm{C}$ at the oxygen fraction equal to 0.02 . It increases when oxygen fraction increases up to a plateau around $317-332{ }^{\circ} \mathrm{C}$ above $10 \%$ of oxygen content.

Finally, it is interesting to note that the results obtained for similar chars are quite close. Then it become possible to identify and to distinguish the main groups of materials studied in this work: charring polymers, flax (i.e. lignocellulosic) fibers, poly butylene terephthalate containing inorganic additives and phosphorus containing polymers (both polyamide and epoxy). We discuss these results in the following section according to the materials group.

\subsection{Charring polymers}

Three charring polymers were tested: polycarbonate (char content in anaerobic pyrolysis equal to 24\%), poly( etheretherketone) (char content: $40 \%$ ) and polybutylene tere phthalate (char content: 6\%). The chars exhibit very close properties: $\mathrm{T}_{1}$ ranges from 707 to $728 \mathrm{~K}$ (i.e. from 434 to $455^{\circ} \mathrm{C}$ ) and $\alpha$ ranges from 0.063 to 0.081 (Fig. 5 and Table 2). This is not

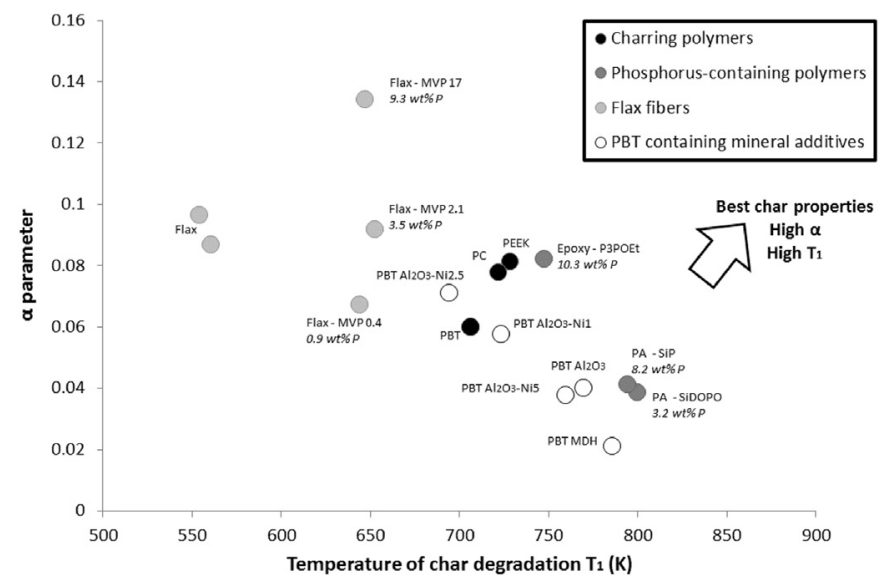

Fig. 5. $\alpha$ parameter versus $T_{1}$ for all studied chars prepared according to the standard procedure (labels in italic correspond to the phosphorus content in the char). 
Table 1

Materials studied in this work.

\begin{tabular}{|c|c|c|c|c|}
\hline Char from & Test conditions & Additive & Initial content (wt\%) & Phosphorus content in the char (wt\%) \\
\hline PEEK & Standard procedure & 1 & 1 & 0 \\
\hline PC & Standard procedure & l & l & 0 \\
\hline PBT & Standard procedure & 1 & l & 0 \\
\hline Epoxy-P3P(OEt) & Standard procedure & P3P(OEt) & 17.2 & 10.3 \\
\hline Epoxy-P3P(OEt) & Cone residue & P3P(OEt) & 17.2 & 10.3 \\
\hline Epoxy-AРP & Cone residue & APP & 9.4 & 11.6 \\
\hline PA-SiP & Standard procedure & SiP & 11 & 8.2 \\
\hline PA-SiDOPO & Standard procedure & SiDOPO & 10 & 3.2 \\
\hline Flax fibers & Standard procedure & 1 & l & 0 \\
\hline Flax fibers & Direct aerobic pyrolysis & i & l & 0 \\
\hline Flax-MVP 0.4 & Standard procedure & MVP & 0.4 & 0.9 \\
\hline Flax-MVP 0.4 & Direct aerobic pyrolysis & MVP & 0.4 & Unknown \\
\hline Flax-MVP 2.1 & Standard procedure & MVP & 2.1 & 3.5 \\
\hline Flax-MVP 2.1 & Direct aerobic pyrolysis & MVP & 2.1 & Unknown \\
\hline Flax MVP 17 & Standard procedure & MVP & 17 & 9.3 \\
\hline Flax-MVP 17 & Direct aerobic pyrolysis & MVP & 17 & Unknown \\
\hline PBT-MDH & Standard procedure & $\mathrm{MDH}$ & 10 & 0 \\
\hline PBT-alumina & Standard procedure & Alumina & 10 & 0 \\
\hline PBT-alumina Ni1 & Standard procedure & Modified alumina & 10 & 0 \\
\hline PBT-alumina Ni2.5 & Standard procedure & Modified alumina & 10 & 0 \\
\hline PBT-alumina Ni5 & Standard procedure & Modified alumina & 10 & 0 \\
\hline Nanodiamond ND & Direct aerobic pyrolysis & 1 & 1 & $0^{\mathrm{a}}$ \\
\hline ND3.85 & Direct aerobic pyrolysis & Phosphate & i & $3.85^{\mathrm{a}}$ \\
\hline ND3.99 & Direct aerobic pyrolysis & Phosphate & i & $3.99^{\mathrm{a}}$ \\
\hline ND5.15 & Direct aerobic pyrolysis & Phosphate & i & $5.15^{\mathrm{a}}$ \\
\hline
\end{tabular}

a Phosphorus content in nanodiamonds.

Table 2

Main data on thermo-oxidative stability for the studied chars.

\begin{tabular}{|c|c|c|c|c|c|c|c|c|c|}
\hline Char from & Test conditions & $\mathrm{T}_{0.01} f_{\mathrm{O}_{2}}$ & 0.01 & $\mathrm{~T}_{0.2} f_{\mathrm{O}_{2}}$ & 0.2 & $\mathrm{~T}_{1}(\mathrm{~K}) f_{\mathrm{O}_{2}}$ & 1 & $\alpha$ & $\mathrm{R} 2$ \\
\hline PEEK & Standard procedure & 1059 & & 833 & & 728 & & 0.081 & 0.9939 \\
\hline PC & Standard procedure & 1034 & & 823 & & 721 & & 0.078 & 0.9981 \\
\hline PBT & Standard procedure & 932 & & 792 & & 706 & & 0.060 & 0.9617 \\
\hline Epoxy-P3P(OEt) & Standard procedure & 1092 & & 842 & & 747 & & 0.083 & 0.9822 \\
\hline Epoxy-P3P(OEt) & Cone residue & 1094 & & 946 & & 859 & & 0.053 & 0.9457 \\
\hline Epoxy-APP & Cone residue & 1060 & & 955 & & 900 & & 0.036 & 0.9572 \\
\hline PA-SiP & Standard procedure & 962 & & 858 & & 794 & & 0.042 & 0.9553 \\
\hline PA-SiDOPO & Standard procedure & 956 & & 845 & & 799 & & 0.039 & 0.9433 \\
\hline \multirow{2}{*}{ Flax fibers } & Standard procedure & 865 & & 624 & & 554 & & 0.097 & 0.9607 \\
\hline & & 836 & & 626 & & 560 & & 0.087 & 0.9741 \\
\hline Flax fibers & Direct aerobic pyrolysis & 871 & & 668 & & 600 & & 0.081 & 0.957 \\
\hline Flax-MVP 0.4 & Standard procedure & 878 & & 718 & & 643 & & 0.068 & 0.9815 \\
\hline Flax-MVP 0.4 & Direct aerobic pyrolysis & 919 & & 735 & & 660 & & 0.072 & 0.9939 \\
\hline Flax-MVP 2.1 & Standard procedure & 997 & & 749 & & 652 & & 0.092 & 0.9796 \\
\hline Flax-MVP 2.1 & Direct aerobic pyrolysis & 959 & & 769 & & 679 & & 0.075 & 0.9962 \\
\hline Flax MVP 17 & Standard procedure & 1201 & & 780 & & 647 & & 0.135 & 0.9523 \\
\hline Flax-MVP 17 & Direct aerobic pyrolysis & 1157 & & 788 & & 669 & & 0.119 & 0.9621 \\
\hline PBT-MDH & Standard procedure & 866 & & 811 & & 785 & & 0.021 & 0.9847 \\
\hline PBT-alumina & Standard procedure & 925 & & 827 & & 769 & & 0.040 & 0.9805 \\
\hline PBT-alumina Ni1 & Standard procedure & 944 & & 794 & & 723 & & 0.058 & 0.9761 \\
\hline PBT-alumina Ni2.5 & Standard procedure & 963 & & 793 & & 694 & & 0.071 & 0.9707 \\
\hline PBT-alumina Ni5 & Standard procedure & 904 & & 801 & & 759 & & 0.038 & 0.9891 \\
\hline
\end{tabular}

surprising because these polymers contain only $\mathrm{C}, \mathrm{O}$ and $\mathrm{H}$ atoms and the corresponding chars must exhibit similar chemical com positions. Lyon et al. have shown that chars resulting from many charring polymers have elemental compositions close to $\mathrm{C}_{5} \mathrm{H}_{2}$ [34].

The effective heat of combustion (EHC) of these chars was calculated as the ratio between the total heat release (THR) and the mass loss (ML). The effective heat of combustion depends on the elemental composition according to Huggett's relation [35]: $1 \mathrm{~kg}$ of oxygen consumed during combustion corresponds to $13.1 \mathrm{MJ}$ of energy released. To ensure a complete degradation of the char, its pyrolysis was carried out at an oxygen fraction of oxygen equal to $40 \%$. The EHC of PEEK and PC were found to be respectively equal to 30.6 and $30.8 \mathrm{~kJ} / \mathrm{g}$. Unfortunately, the char content of PBT was too low $(<10 \mathrm{wt} \%)$ to calculate accurately its EHC. Note that the calculated EHC for PEEK and PC are slightly lower than expected from literature [36]. The reasons may be twofold. First Lyon et al. [34] have shown that the heat of combustion in PCFC slightly de creases when the oxygen fraction increases. Second, the heat release would be slightly underestimated by our apparatus.

\subsection{Epoxy and polyamide flame retarded with phosphorus additives}

The chars prepared from flame retarded polymers according to the standard procedure exhibit higher stabilities in pure oxygen than charring polymers studied just above (Fig. 7). The temperature $\mathrm{T}_{1}$ is high: $747 \mathrm{~K}$ for the epoxy flame retarded with P3P(OEt) and 795-800 K for the polyamides flame retarded with SiP and SiDOPO 


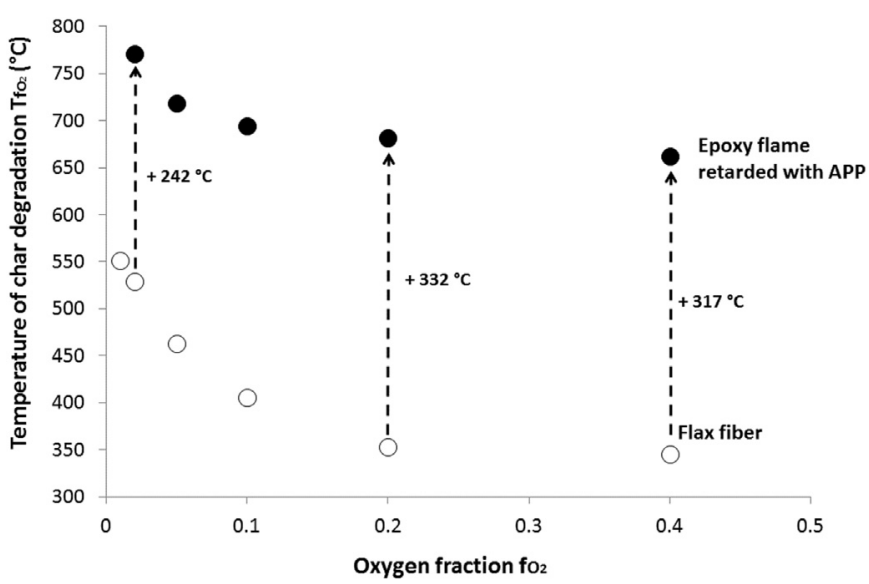

Fig. 6. Temperature of char degradation versus the oxygen fraction for a char prepared from untreated flax fiber (standard procedure, open circles) and for a char prepared from epoxy containing ammonium polyphosphate (sampled from the cone calorimeter test, black circles).

and the parameter $\alpha$ is very low for the two polyamide based materials (around 0.04) but much higher for the flame retarded epoxy (0.0825). It is interesting to note that the chars resulting from polyamide based materials exhibit higher temperature $T_{1}$ despite a lower phosphorus content (3.2, 8.2 and $10.3 \mathrm{wt} \%$ respectively for the polyamides flame retarded by SiDOPO, SiP and flame retarded epoxy). Moreover, SiDOPO seems to promote a more stable char in comparison to SiP: the char properties are similar but the phos phorus content is much lower in the first case. This fact may be not related to the presence of silicon in the char. The silicon content is $19.5 \mathrm{wt} \%$ for the char from the polyamide flame retarded with SiP and only $16.4 \mathrm{wt} \%$ for the char prepared from the polyamide flame retarded with SiDOPO.

The chars obtained from the cone calorimeter tests exhibit significantly better thermal stability. The parameters $T_{1}$ and $\alpha$ are in the range $860-900 \mathrm{~K}$ and $0.35-0.53$, respectively. In particular, the char arising from the epoxy flame retarded with $\mathrm{P} 3 \mathrm{P}(\mathrm{OEt})$ exhibits higher $\mathrm{T}_{1}$ and lower $\alpha$ after the cone calorimeter test than according to the standard procedure, despite the same phosphorus content (10.3 wt\%). This observation may be explained by a deeper thermo oxidation of a char fraction at the end of the cone calorimeter test. This point needs further investigation to be confirmed.

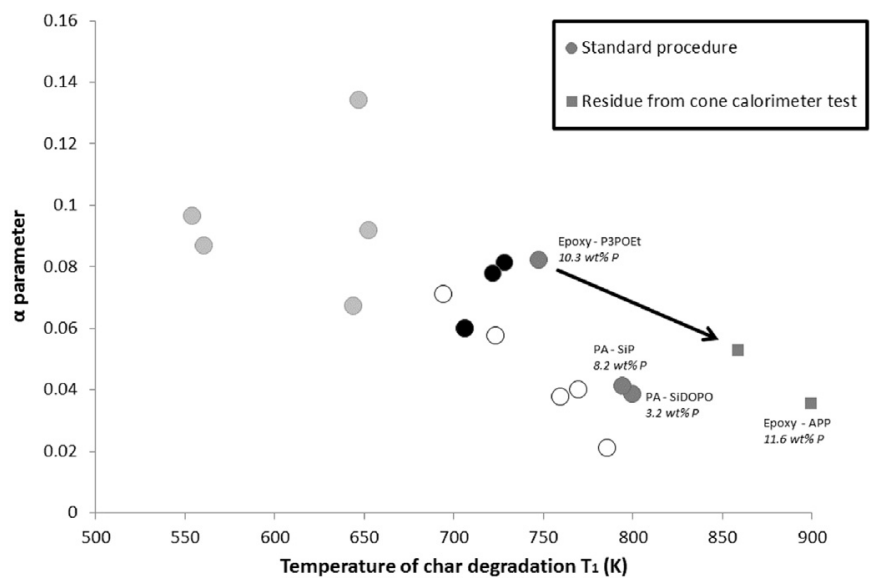

Fig. 7. Thermo-oxidative stability for epoxy and polyamide-based materials flame retarded with phosphorus-containing additives according to two procedures for char preparation (only the chars discussed in this section are labelled).

\subsection{Flame retarded flax fibers}

The chars obtained from flax fibers using standard procedure exhibit low $\mathrm{T}_{1}$ (Fig. 8). $\mathrm{T}_{1}$ was in the range $554-560 \mathrm{~K}$ (i.e. $281-287^{\circ} \mathrm{C}$ ) and $\alpha$ was found to be in the range $0.087-0.097$ (high sensitivity to the oxygen fraction). The grafting of phosphorus compound (dimethylvinyl phosphonate MVP) on flax fibers allows an increase of $\mathrm{T}_{1}$ up to 643-652 $\mathrm{K}$. This value was the same whichever the phosphorus content in the char (0.9-9.3 wt\%).

The changes in $\alpha$ were observed to be more complex. The lowest $\alpha(0.068)$ was obtained for the char containing $0.9 \mathrm{wt} \%$ of phos phorus. However, the $\alpha$ value increased up to 0.13 when the phosphorus content increases up to $9.3 \mathrm{wt} \%$. Such a value is very high and indicates a strong sensitivity to the oxygen fraction in air. It also means that the char becomes the most thermally stable when the oxygen fraction is the lowest. Its degradation tempera ture for an oxygen fraction of 0.01 is found equal to $1200 \mathrm{~K}$, higher than the degradation temperature of the char prepared from epoxy composite flame retarded with APP.

A comparison of the chars prepared using the standard pro cedure or using a direct aerobic pyrolysis of the material provides a consistent tendency: $\mathrm{T}_{1}$ increases from 554 to $600 \mathrm{~K}$ for untreated flax fibers and from $643-652$ to $660-679 \mathrm{~K}$ for treated fibers. $\alpha$ seems to decrease when a direct aerobic pyrolysis is applied. $\alpha$ is stable around $0.068-0.072$ according to both methods only in the case of flax fibers containing $0.4 \mathrm{wt} \%$ of MVP. This seems to be consistent with the observations of Sun et al. who found that the chars prepared in presence of a small amount of oxygen (1\%) has lower reactivity than the chars prepared from anaerobic pyrolysis [8].

The same conclusions can be drawn on the influence of phos phorus content: $T_{1}$ does not change appreciably and $\alpha$ increases when the phosphorus content increases whichever the procedure used (standard procedure or direct aerobic pyrolysis).

In the whole, the influence of phosphorus on the thermo oxidative stability is complex. It seems that only a small content of phosphorus is needed to improve slightly the thermo oxidative stability. Higher phosphorus content does not improve anymore the thermo oxidative stability but increases the char content. The chars resulting from flax fibers modified with high content of dimethylvinyl phosphonate (MVP) do not reach the same thermo oxidative stability as charring polymers. Nevertheless, even a slight increase in thermo oxidative stability improves significantly the

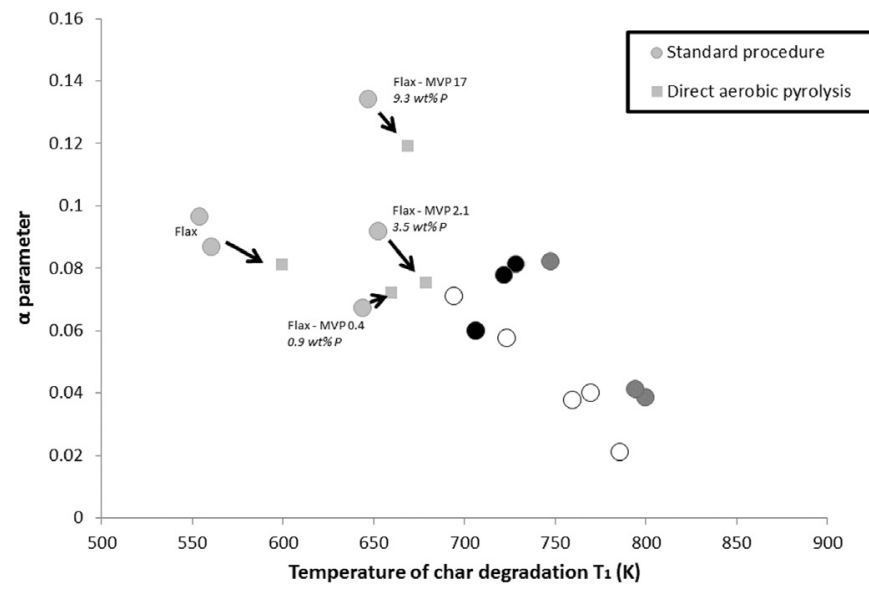

Fig. 8. Thermo-oxidative stability of flax fibers grafted with MVP according to the standard procedure or determined during their direct aerobic pyrolysis (only the chars discussed in this section are labelled). 
behavior of a fabric prepared from flax fibers during a fire test, as proved in a recent publication [2].

\subsection{Polybutylene terephthalate containing mineral additives}

The use of phosphorus containing flame retardants allows modifying the thermo oxidative stability of the char but also increasing significantly the char content. It is a well known effect of these additives. However, other additives can also act as efficient char promoters. Viretto et al. [20] had shown that only $10 \mathrm{wt} \%$ of magnesium hydroxide and magnesium oxide can increase signifi cantly the char amount from PBT degradation and thus modify the char properties.

Recently, we have observed that alumina and alumina modified with nickel elaborated following the procedure described by Majoli et al. [28] do not only lead to an enhancement of the char amount from PBT pyrolysis but also changes its properties in a certain extent.

Pure alumina and magnesium hydroxide (MDH) change the thermo oxidative stability of the char. $\mathrm{T}_{1}$ increases up to $785 \mathrm{~K}$ in presence of $\mathrm{MDH}$ and $\alpha$ decreases. The presence of nickel at the surface of alumina particles leads to a slight decrease in thermo oxidative stability in comparison of pure alumina. Nevertheless, the change in char properties does not follow a clear tendency according to nickel content and further research will focus on this issue.

Interestingly, it can be observed that all the data points corre sponding to this series are aligned. Higher char stability under pure oxygen is closely related to lower sensitivity to oxygen.

\subsection{Influence of elemental composition of the char on its thermo oxidative stability}

The elemental compositions of all chars were investigated by Energy Dispersive X ray spectroscopy (EDX) coupled to scanning electron microscopy (Table 3). It appears that there is no simple relation between the elemental composition and the thermo oxidative stability of char. Indeed, some chars exhibiting similar phosphorus content (around 9-12 wt\%, both for chars prepared from flax MVP17 and from epoxy P3POEt) exhibit very different $\mathrm{T}_{1}$ $\left(920-1173 \mathrm{~K}\right.$, i.e. $\left.647-900{ }^{\circ} \mathrm{C}\right)$. In the whole, contrarily to the effective heat of combustion which can be calculated from the elemental composition, the char thermo oxidative stability during an aerobic pyrolysis depends on a couple of parameters, as already explained in the introduction part.

Concerning more specifically the chars prepared from fire tests, several researchers have assumed the influence of various param eters. Hence a higher degree of graphitization measured from the ratio between $D$ and $G$ bands intensities arising from Raman spectroscopy data corresponds to more thermally stable char $[37,38]$. Shao et al. considered that the presence of $\mathrm{P}-\mathrm{N}-\mathrm{C}$ bonds improves the char thermal stability $[39,40]$. Quach et al. observed that the decomposition of PMMA flame retarded with ammonium polyphosphate (APP) and silica leads to a more insulating char when $\mathrm{SiP}_{2} \mathrm{O}_{7}$ crystals are formed by a chemical reaction between APP and silica [41]. Unfortunately, no quantitative relation was drawn between the composition and the structure of the chars and their thermo oxidative stability. Further research is needed to ascertain such relations.

At the same time, it may be noted that there is just a rough relation between the carbon weight fraction, $\mathrm{T}_{1}$ and $\alpha$. A low carbon fraction allows reaching higher $\mathrm{T}_{1}$ and lower $\alpha$.

It can also be confirmed (Table 3 ) that the char sampled from the cone calorimeter test exhibits a better thermo oxidative stability (higher $\mathrm{T}_{1}$ ) than their counterparts prepared using the standard procedure. Indeed, the carbon contents of the chars sampled from the cone calorimeter test are much lower. For example, the carbon content of the char prepared from epoxy material flame retarded with $\mathrm{P} 3 \mathrm{P}(\mathrm{OEt})$ is $56.8 \mathrm{wt} \%$ after the cone calorimeter test against $77.4 \mathrm{wt} \%$ when the standard procedure was applied. This fact is probably due to an extended thermo oxidation step at the end of the cone calorimeter test when the flame is vanished.

During a fire test, a char can act according to two different modes. Firstly, it reduces the heat release by trapping carbon into the condensed phase. Higher is the carbon content in the char higher is its "potential" effective heat of combustion and lower is the heat actually released during the thermal degradation of a material. However, it can also act as a layer insulating the under lying polymer. From this point of view, higher is its thermal sta bility, better is its efficiency to slowdown the thermal degradation.

Combining these two modes of action is challenging because a high carbon content corresponds to a lower thermal stability. It appears quite difficult to obtain a char storing a lot of energy with a high thermal stability as shown in Fig. 9. Effective heat of com bustion was calculated considering a complete oxidation and the composition based only on C, O, P and Si atoms (representing more than $96 \mathrm{wt} \%$ of the char composition).

\subsection{Phosphorylated nanodiamonds}

Due to the very high thermo oxidative stability of nano diamonds, the procedure was modified to study these materials. The temperature considered to assess their stability is the tem perature for which the heat release rate reaches $50 \mathrm{~W} / \mathrm{g}$ (and not the temperature of the peak of heat release rate). Obviously the parameters $T_{1}$ and $\alpha$ calculated according to this method cannot be

Table 3

Elemental compositions of several studied chars.

\begin{tabular}{|c|c|c|c|c|c|c|c|c|}
\hline \multirow[t]{2}{*}{ Char obtained from } & \multirow[t]{2}{*}{ Test conditions } & \multirow{2}{*}{$\mathrm{T}_{1}(\mathrm{~K}) f_{\mathrm{O}_{2}}$} & \multirow[t]{2}{*}{1} & \multirow[t]{2}{*}{$\alpha$} & \multicolumn{4}{|c|}{ Weight fraction (\%) } \\
\hline & & & & & $\mathrm{C}$ & $\mathrm{O}$ & $\mathrm{P}$ & $\mathrm{Si}$ \\
\hline Epoxy-P3P(OEt) & Standard procedure & 747 & & 0.083 & 77.4 & 12.3 & 10.3 & 0 \\
\hline Epoxy-P3P(OEt) & Cone residue & 859 & & 0.053 & 56.8 & 29.5 & 10.3 & 0 \\
\hline Epoxy-APP & Cone residue & 900 & & 0.036 & 51.0 & 33.7 & 11.6 & 0 \\
\hline PA-SiP & Standard procedure & 794 & & 0.042 & 31.5 & 40.0 & 8.3 & 19.5 \\
\hline PA-SiDOPO & Standard procedure & 799 & & 0.039 & 48.7 & 31.7 & 3.2 & 16.4 \\
\hline \multirow[t]{2}{*}{ Flax fibers } & Standard procedure & 554 & & 0.097 & 81.7 & 14.8 & 0 & 0 \\
\hline & & 560 & & 0.087 & & & & \\
\hline Flax-MVP 0.4 & Standard procedure & 643 & & 0.068 & 87.9 & 9.5 & 0.9 & 0 \\
\hline Flax-MVP 2.1 & Standard procedure & 652 & & 0.092 & 84.3 & 11.5 & 3.5 & 0 \\
\hline Flax MVP 17 & Standard procedure & 647 & & 0.135 & 76.9 & 13.5 & 9.3 & 0 \\
\hline
\end{tabular}




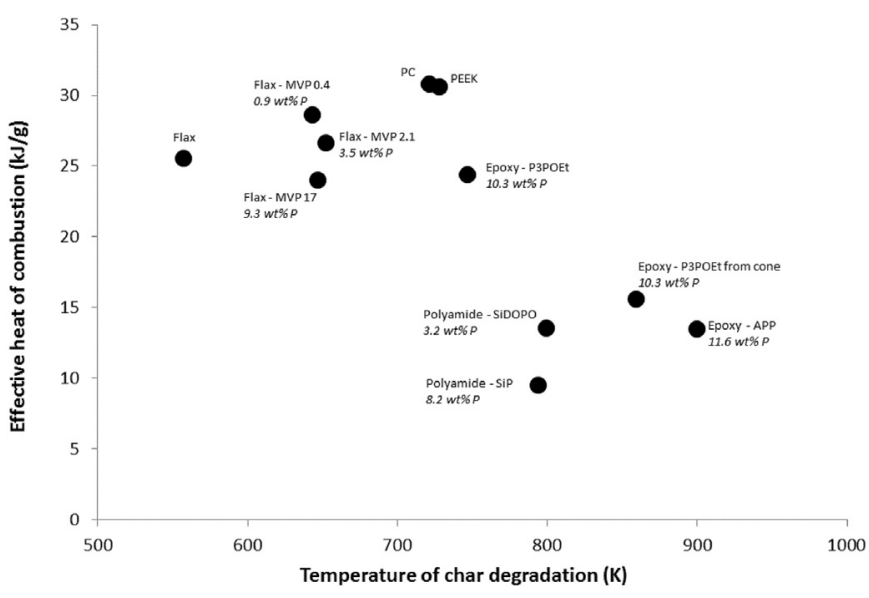

Fig. 9. Effective heat of combustion versus the thermal stability in pure oxygen $\left(T_{1}\right)$ for the chars listed in Table 3 (EHC of PEEK and PC experimentally measured was also added).

compared to the parameters calculated using the standard method.

Table 4 and Fig. 10 summarize the results obtained with un modified and phosphorylated nanodiamonds. It appears that phosphorus leads to a strong improvement of thermo oxidative stability in good agreement with previous findings [29] (see supporting information S2). For unmodified nanodiamonds, the temperatures allowing to reach a heat release rate equal to $50 \mathrm{~W} / \mathrm{g}$ in pure oxygen and in air $\left(f_{\mathrm{O}_{2}} \quad 0.2\right)$ are $691 \mathrm{~K}$ and $726 \mathrm{~K}$ respec tively. In the case of nanodiamonds containing $5.15 \mathrm{wt} \%$ of phos phorus, these temperatures rise correspondingly, up to $938 \mathrm{~K}$ and $965 \mathrm{~K}$. The increase of temperature is thus about $250 \mathrm{~K}$. Once again, the influence of phosphorus appears nonlinear. Especially, $\alpha$ does not change when phosphorus content increases up to $4 \mathrm{wt} \%$ but starts decreasing with a further increase in phosphorus content (ND5.15).

\section{Conclusions}

A simple method for an evaluation of the thermo oxidative stability of chars collected from burnt polymers is proposed. The method is based on the application of the pyrolysis combustion flow calorimetry in a broad range of the oxygen contents in py rolysis chamber- from $0 \%$ vol. (anaerobic conditions) up to $40 \% \mathrm{vol}$. The method allows defining two main parameters which charac terize the thermo oxidative properties of the char, namely the temperature $T_{1}$ of char degradation in pure oxygen and the value $\alpha$ representing the dependence of the char degradation temperature on the oxygen fraction.

$\alpha$ usually decreases when $T_{1}$ increases. This is likely to mean that a low thermo oxidative stability of a char in pure oxygen (low $\mathrm{T}_{1}$ ) causes it to become highly sensitive to the oxygen content. How ever, the best thermo oxidative profile should correspond both to high $\mathrm{T}_{1}$ and $\alpha$ values. Nevertheless, it depends also on the burning

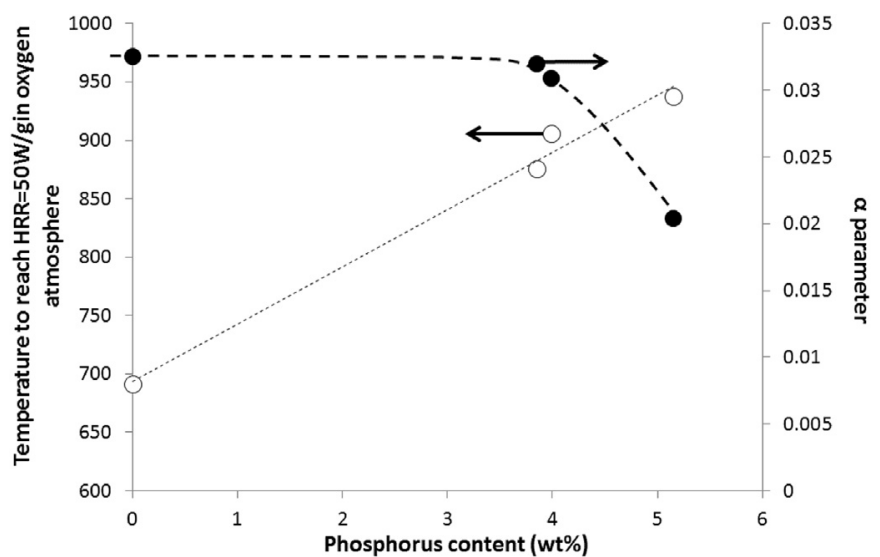

Fig. 10. Evolution of the nanodiamonds properties versus the phosphorus content on nanodiamonds (white circles: calculated temperature for a heat release rate (HRR) equal to $50 \mathrm{~W} / \mathrm{g}$ in pure oxygen; black circles: alpha parameter).

conditions. For an aerobic pyrolysis in an atmosphere relatively rich in oxygen (the oxygen fraction arises to 0.1 and more), a high $\mathrm{T}_{1}$ value must be targeted. On the contrary, if pyrolysis is carried out in an atmosphere poor in oxygen, a high $\alpha$ value can compensate a low temperature $\mathrm{T}_{1}$.

Due to a broad range of materials studied in this work (ligno cellulosic fibers, synthetic polymers, carbon based composite ma terials, polymers containing phosphorus flame retardants, organ ophosphorus silica and metal based fillers), it appears quite difficult to point out any general relationships between the char elemental composition and its thermo oxidative stability. However, some particular observations can be already made.

First of all, high carbon content appears to be harmful for the thermo oxidative stability of a material. Combining high thermal stability and great energy storage capacity is a challenging task. Further work is needed to link the thermo oxidative stability and the structure of the char.

One of the main expected results concerns the influence of phosphorus on the thermo oxidative stability. Phosphorus im proves the temperature of char degradation and allows chars to be thermally stable during fire tests even in aerobic conditions. Nevertheless, the effect of phosphorus also depends strongly on the materials composition. Even with high content of phosphorus, chars from ligno cellulosic fibers exhibit low thermo oxidative stability. On the contrary, in the case of epoxy, polyamide or nanodiamonds, the char degradation temperature can reach or exceed $800 \mathrm{~K}$. The sensitivity of char degradation to the oxygen fraction also changes with the phosphorus content but no clear tendency can be noted.

It must be also mentioned that the conditions of char elabora tion are highly influent on the char properties. In particular, the chars obtained from the cone calorimeter test or from direct aer obic pyrolysis usually manifest better thermo oxidative stabilities than those prepared from anaerobic pyrolysis in PCFC.

Table 4

Main data on thermo-oxidative stability of nanodiamonds.

\begin{tabular}{|c|c|c|c|c|c|c|c|}
\hline Char from & Test conditions & $\mathrm{T}_{0.2}(\mathrm{~K}) f_{\mathrm{O}_{2}}$ & 0.2 & $\mathrm{~T}_{1}(\mathrm{~K}) f_{\mathrm{O}_{2}}$ & 1 & $\alpha$ & $\mathrm{R} 2$ \\
\hline ND & Direct aerobic pyrolysis & 726 & & 691 & & 0.0325 & 0.9925 \\
\hline ND3.85 & Direct aerobic pyrolysis & 917 & & 875 & & 0.032 & 0.9922 \\
\hline ND3.99 & Direct aerobic pyrolysis & 951 & & 906 & & 0.0309 & 0.9802 \\
\hline ND5.15 & Direct aerobic pyrolysis & 965 & & 938 & & 0.0204 & 0.9673 \\
\hline
\end{tabular}




\section{Acknowledgments}

The authors thank the french "Fonds Unique Interministériel" the french "Pôles de Compétitivité" for supporting the BIONICOMP project. J. Sahyoun and R. Ménard are acknowledged to have pre pared some materials studied in this article.

\section{Appendix A. Supplementary data}

Supplementary data related to this article can be found at http:// dx.doi.org/10.1016/j.polymdegradstab.2016.11.007.

\section{References}

[1] R.H. Kramer, M. Zammarano, G.T. Linteris, U.W. Gedde, J.W. Gilman, Heat release and structure collapse of flexible polyurethane foam, Polym. Degrad. Stab. 95 (2010) 11151122.

[2] R. Sonnier, B. Otazaghine, A. Viretto, G. Apolinario, P. Ienny, Improving the flame retardancy of flax fabrics by radiation grafting of phosphorus compounds, Eur. Polym. J. 68 (2015) 313325.

[3] P.L. Walker, R.L. Taylor, J.M. Ranish, An update on the carbon-oxygen reaction, Carbon 3 (1991) 411421.

[4] I.W. Smith, The intrinsic reactivity of carbons to oxygen, Fuel 57 (1978) 409414.

[5] L. Schoening, X-ray structural parameter for coal, Fuel 61 (1982) 695699.

[6] L. Lu, V. Sahajwalla, C. Kong, D. Harris, Quantitative X-ray diffraction analysis and its application to various coals, Carbon 39 (2001) 18211833.

[7] A.M. Rao, E. Richter, S. Bandow, B. Chase, P.C. Eklund, K.A. Willams, S. Fang, K.R. Subbaswamy, M. Menon, A. Thess, R.E. Smalley, G. Dresselhaus, M.S. Dresselhaus, Diameter-selective Raman scattering from vibrational modes in carbon nanotubes, Science 275 (1997) 187191.

[8] J.-L. Sun, X.-J. Chen, F. Wang, X.-C. Lin, Y.-G. Wang, Effects of oxygen on the structure and reactivity of char during steam gasification of Shengli brown coal, J. Fuel Chem. Technol. 43 (2015) 769778.

[9] N. Russell, J. Gibbins, J. Williamson, Structural ordering in high temperature coal chars and the effect on reactivity, Fuel 78 (1999) 803807.

[10] K. McDonald, W. Hyde, W. Hecker, Low temperature char oxidation kinetic: effect of preparation method, Fuel 71 (1992) 319323.

[11] L. Lu, C. Kong, V. Sahajwalla, D. Harris, Char structural ordering during pyrolysis and combustion and its influence on char reactivity, Fuel 81 (2002) 12151225 .

[12] I. Smith, R. Tyler, Internal burning of pulverized semi-anthracite: the relation between particle structure and reactivity, Fuel 51 (1972) 312321.

[13] W. Wells, L. Smoot, Relation between reactivity and structure for coals and chars, Fuel 70 (1991) 454458.

[14] L. Radovic, P. Walker, Reactivities of chars obtained as residues in selected coal conversion processes, Fuel Process. Technol. 8 (1984) 149154.

[15] H.-Y. Cai, A. Güell, I. Chatzakis, J.-Y. Lim, D. Dugwell, R. Kandiyoti, Combustion reactivity and morphological change in coal chars: effect of pyrolysis temperature, heating rate and pressure, Fuel 75 (1996) 1524.

[16] K. Davis, R. Hurt, N. Yang, T. Headley, Evolution of char chemistry, crystallinity, and ultrafine structure during pulverized-coal combustion, Combust. Flame 100 (1995) 3140.

[17] ASTM D7309, 2011.

[18] B. Perret, K.H. Pawlowski, B. Schartel, Fire retardancy mechanisms of arylphosphates in polycarbonate (PC) and PC/acrylonitrile-butadiene-styrene: the key role of decomposition temperature, J. Therm. Analysis Calorim. 97 (2009) 949958.

[19] B. Schartel, B. Perret, B. Dittrich, M. Ciesielski, J. Kramer, P. Müller, V. Altstadt, L. Zang, M. Doring, Flame retardancy of polymers: the role of specific reactions in the condensed phase, Macromol. Mater. Eng. 301 (2016) 935.

[20] A. Viretto, R. Sonnier, A. Taguet, B. Otazaghine, L. Ferry, J.-M. Lopez-Cuesta, C. Lagrève, Thermal degradation of polyesters filled with magnesium dihydroxide and magnesium oxide, Fire Mater. 40 (2016) 445463.
[21] R. Kozłowski, M. Władyka-Przybylak, Flammability and fire resistance of composites reinforced by natural fibers, Polym. Adv. Technol. 19 (2008) 446453.

[22] D. Maldas, B.V. Kokta, J.C. Daneaulf, Influence of coupling agents and treatments on the mechanical properties of cellulose fiber-polystyrene composites, J. Appl. Polym. Sci. 37 (1989) 751775.

[23] A. Khalil, H.D. Rozman, N.N. Ahmad, H. Ismail, Acetylated plant-fiberreinforced polyester composites: a study of mechanical, hygro-thermal, and aging characteristics, Polymer-Plastics Technol. Eng. 39 (2000) 757781.

[24] B.D. Pallensen, The quality of combine-harvested fibre flax for industrials purposes depends on the degree of retting, Industrial Crops Prod. 5 (1996) 6578.

[25] R. Ménard, C. Negrell-Guirao, L. Ferry, R. Sonnier, G. David, Synthesis of biobased phosphate flame retardants - characterization of flame retardancy on epoxy thermosets, Pure Appl. Chem. 86 (2014) 16371650.

[26] J. Sahyoun, V. Bounor-Legaré, L. Ferry, R. Sonnier, A. Bonhommé, P. Cassagnau, Influence of organophosphorus silica precursor on the thermal and fire behaviour of a PA66/PA6 copolymer, Polym. Degrad. Stab. 115 (2015) 117128.

[27] J. Sahyoun, V. Bounor-Legaré, L. Ferry, R. Sonnier, F. Da Cruz-Boisson, F. Melis, A. Bonhommé, P. Cassagnau, Synthesis of a new organophosphorous alkoxysilane precursor and its effect on the thermal and fire behavior of a PA66/PA6 copolymer, Eur. Polym. J. 66 (2015) 352366.

[28] L. Majoli, A. Evstratov, J.M. Guillot, A. Rouvière, P. Baussand, Composite carbon nanostructures as promising carriers for gaz analysis, NSTI-Nanotech 1 (2006) 146149.

[29] C. Presti, J.G. Alauzun, D. Laurencin, P.H. Mutin, Improvement of the Oxidative Stability of Nanodiamonds by Surface Phosphorylation, Chem. Mater. 25 (2013) 20512055 .

[30] D. Marquis, B. Batiot, E. Guillaume, T. Rogaume, Influence of reaction mechanism accuracy on the chemical reactivity prediction of complex charring materials in fire condition, J. Anal. Appl. Pyrolysis 118 (2016) 231248.

[31] D. Marquis, E. Guillaume, A. Camillo, T. Rogaume, F. Richard, Existence and uniqueness of solutions of a differential equation system modeling the thermal decomposition of polymer materials, Combust. Flame 160 (2013) 818829.

[32] G. Rein, C. Lautenberger, A. Fernandez-Pello, J. Torero, D. Urban, Application of genetic algorithms and thermogravimetry to determine the kinetics of polyurethane foam in smoldering combustion, Combust. Flame 146 (2006) 95108.

[33] S.-Q. Hu, F. You, The effects of oxygen contents and heating rates on characteristics of pyrolysis prior to smoldering of flexible polyurethane foam, Procedia Eng. 52 (2013) 145151.

[34] R. Walters, N. Safronava, R. Lyon, A microscale combustion calorimeter study of gas phase combustion of polymers, Combust. Flame 162 (2015) 855863.

[35] C. Huggett, Estimation of rate of heat release by means of oxygen consumption measurements, Fire Mater. 4 (1980) 6165

[36] A. Factor, Char formation in aromatic engineering polymers, in: G.L. Nelson (Ed.), Fire and Polymers Hazards Identification and Prevention, ACS Symposium Series, ACS, Washington, 1990, pp. 274287.

[37] K. Zhou, J. Liu, Y. Shi, S. Jiang D. Wang, Y. Hu, Z. Gui, MoS2 nanolayers grown on carbon nanotubes: an advanced reinforcement for epoxy composites, ACS Appl. Mater. Interfaces 7 (2015) 60706081.

[38] R. Rajarao, I. Mansuri, R. Dhunna, R. Khanna, V. Sahajwalla, Study of structural evolution of chars during rapid pyrolysis of waste CDs at different temperatures, Fuel 134 (2014) 1725.

[39] Z.-B. Shao, C. Deng, Y. Tan, M.-J. Chen, L. Chen, Y.-Z. Wang, Flame retardation of polypropylene via a novel intumescent flame retardant: ethylenediaminemodified ammonium polyphosphate, Polym. Degrad. Stab. 106 (2014) 8896.

[40] Z.-B. Shao, C. Deng, Y. Tan, M.-J. Chen, L. Chen, Y.-Z. Wang, An efficient monocomponent polymeric intumescent flame retardant for polypropylene preparation and application, ACS Appl. Mater. Interfaces 6 (2014) 73637370.

[41] Y. Quach, N. Cinausero, R. Sonnier, C. Longuet, J.-M. Lopez-Cuesta, Barrie effect of flame retardant systems in poly(methyl methacrylate): Study of the efficiency of the surface treatment by octylsilane of silica nanoparticles in combination with phosphorous fire retardant additives, Fire Mater. 36 (2012) 590602. 